\title{
DEM analyses of constant stress ratio compression and collapsibility tests on unsaturated structural loess
}

\author{
Mingjing Jiang ${ }^{\text {i) }}$, Jiefeng Liu ${ }^{\text {ii) }}$, Tao $\mathrm{Li}^{\text {iii) }}{ }$, Huayang Lei ${ }^{\text {iv) }}$, Xiaofeng $\mathrm{Wu}^{\text {v) }}$ and Pei Cao ${ }^{\text {vi) }}$ \\ i) Professor, Department of Civil Engineering, Tianjin University, No.135, Yaguan road, Tianjin 300350, China; Department of \\ Geotechnical Engineering, Tongji University, No.1239, Siping road, Shanghai 200092, China. \\ ii) Ph. D student, Department of Civil Engineering, Tianjin University, No.135, Yaguan Road, Tianjin 300350, China. \\ iii) Lecturer, Department of Civil Engineering, Tianjin University, No.135, Yaguan Road, Tianjin 300350, China. \\ iv) Professor, Department of Civil Engineering, Tianjin University, No.135, Yaguan Road, Tianjin 300350, China. \\ v) Senior engineer, Department of Geotechnical Engineering, Tongji University, No.1239, Siping road, Shanghai 200092, China. \\ vi) Engineer, Department of Geotechnical Engineering, Tongji University, No.1239, Siping road, Shanghai 200092, China.
}

\begin{abstract}
To investigate the macroscopic and microscopic mechanical behaviors of unsaturated structural loess, threedimensional (3D) distinct element analyses of constant stress ratio (CSR) compression and collapsibility tests were performed. The evolutions of void ratio, deviator strain and bond failure number against vertical stress and water content were analyzed. The results show that the simulations reproduce the main mechanical behaviors of the unsaturated structural loess. The compression tests show that, with stress ratio decreases, the deviator strain and bond failure number increase. The collapsibility tests show that the void ratio decreased with an increases of water content.
\end{abstract}

Keywords: unsaturated structural loess, DEM, compression test, collapsibility test

\section{INTRODUCTION}

Natural loess of large void and weak cementation mainly located in the mid-latitude and semi-arid areas of the world (Pve, 1995; Follmer, 1996; Jefferson et al., 2003). It is structural soil because of including clay, calcium carbonate, and other bond substances between particles. Natural loess performs high strength when its large void and bond structure are not damaged. However, when the interparticle bond in loess is damaged by water immersion, the loess performs collapsibility (Sun et al., 2009), which will lead to engineering and geological hazards, such as collapsing settlement of buildings and high-speed railway foundations (Delage, 2005), rainfall or artificial irrigation induces loess landslide (Xu et al., 2011) and so on.

Macroscopic compression and collapsible deformation properties are related to microstructure evolution. In recent decades, researchers have focused their attention on the microstructure of loess, and they have studied the microstructure of loess by mercury intrusion porosimetry (MIP), scanning electron microscopy (SEM), environmental scanning electron microscopy (ESEM) and computed tomography(CT) (Chen et al., 2009; Jiang et al., 2014; Pu et al., 2000), some microstructures of collapsible loess have been obtained, but can't obtain microscopic data such as interparticle force and bond failure.

Distinct element method (DEM) proposed by Cundall and Strack (1979), is an efficient tool for study microscopic mechanical behaviors of granular material, and can monitor the internal particles, contact, interparticle force and bond failure in real time. $\mathrm{Li}$ et al. (2018) have numerically studied mechanical behaviors of unsaturated structural loess on oedometer and collapsibility tests and Jiang et al. (2019a) have studied mechanical behaviors of unsaturated structural loess on isotropic compression test. Most of the past studies on unsaturated structural loess have been concentrated on simple stress path, unfortunately, limited research has been on CSR tests.

In this paper, the objective of this study is to investigate the mechanical behaviors of unsaturated structural loess at CSR compression and collapsibility tests. The stress ratio denotes the ratio of the third principal stress to the first principal stress, $\mathrm{CSR}=\sigma_{3} / \sigma_{1}$.

\section{CONTACT MODEL, SAMPLE PREPARATION AND SIMULATION METHOD}

\subsection{Contact model}

Based on the 3D bonded contact model, Jiang et al 
Table 1. Parameters of the contact model.

\begin{tabular}{ll}
\hline Parameters & Value \\
\hline Particle density $\left(\mathrm{kg} / \mathrm{m}^{3}\right)$ & 2710 \\
\hline Particle equivalent modulus & 800 \\
\hline Local damping coefficient & 0.7 \\
\hline Particle contact radius coefficient $\beta$ & 0.21 \\
\hline Particle stiffness ratio of normal to tangential & 1.5 \\
\hline
\end{tabular}

(2019b) established a 3D bond contact model of loess by considering the coupling effects of water content-void ratio-suction. Triaxial and collapsibility tests results show that the model can well reproduce the mechanical behaviors of unsaturated structural loess. The calculation process and the physical meaning of the parameters are detailed in their work. This model was used in below simulations. The parameters in simulations are shown in Table 1.

\subsection{Sample preparation}

The particle size distribution curve in this study is shown in Fig. 1. And Fig. 2 shows the DEM sample, which was prepared by Multi-layer with Undercompaction Method (UCM), proposed by Jiang et al (2003). A five-layer cubic test sample contains 42180 particles, and the target void ratio from bottom to top is $1.002,1.001,1.000,0.985$, and 0.945 , respectively.
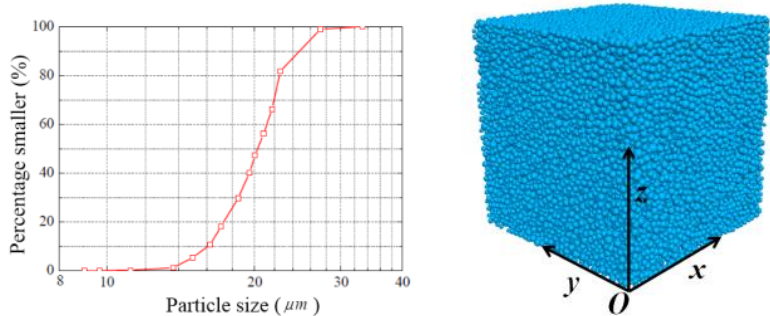

Fig. 1. Particle gradation of DEM sample Fig. 2. DEM sample

\subsection{Simulation method}

The quick wetting $(\mathrm{QW})$ and gradual wetting $(\mathrm{GW})$ tests were performed at the collapsibility test. QW means that the water content is increased to saturated water content rapidly, and GW means that the water content is increased to saturated water content gradually, and the deformation is stabilized after each step of wetting. At first, the CSR compression test is performed, and then under the compression load, the water content of the sample is increased. The macroscopic and microscopic mechanical behaviors of the sample are monitored by DEM. The order of water content in the gradual wetting is $7.1 \%, 9.8 \%, 11.5 \%, 13.8 \%, 16.0 \%$, $18.5 \%, 21.0 \%, 23.0 \%, 26.9 \%$, saturated. The water content of samples in saturated state at different mean stress is about $30 \%$ to $35 \%$.

\section{DEM SIMULATION RESULTS}

\subsection{Void ratio}

Fig. 3 presents the evolutions of void ratio against

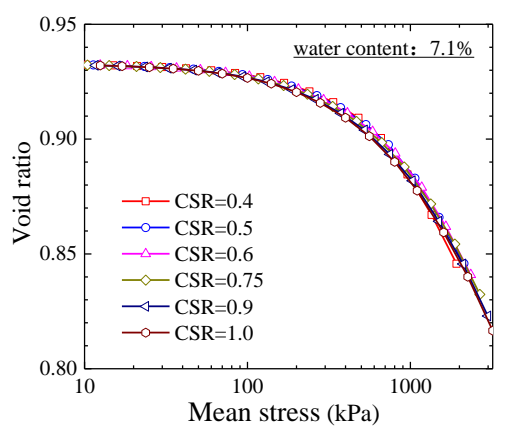

(a)

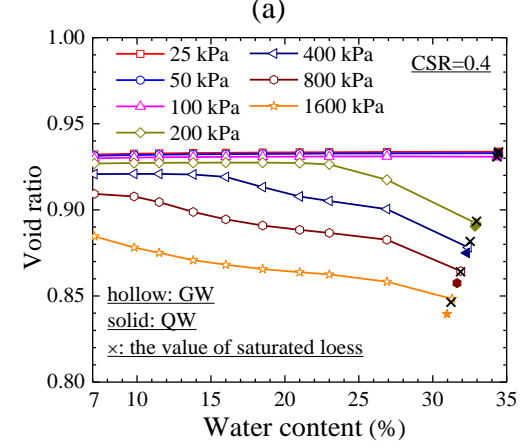

(b)

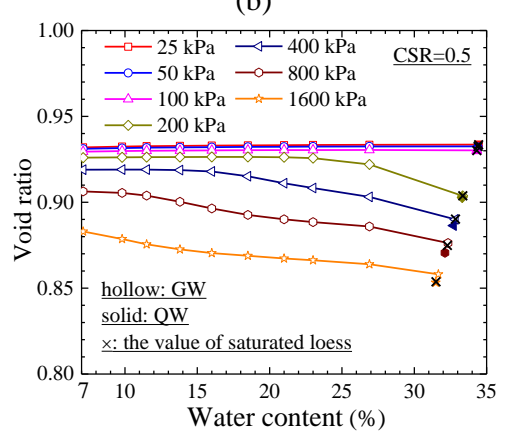

(c)

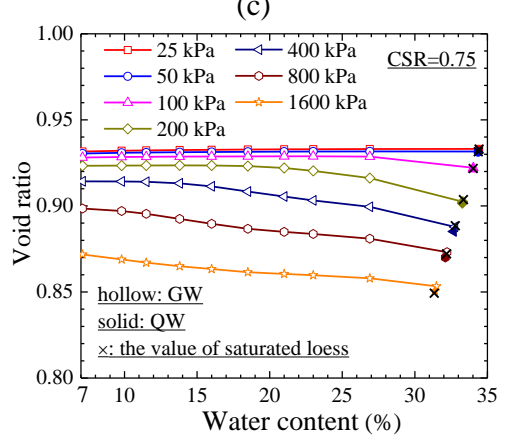

(d)

Fig. 3. Void ratio evolutions of unsaturated structural loess under compression and collapsibility tests at different CSRs: (a) compression test; (b) collapsibility test (CSR=0.4); (c) collapsibility test $(\mathrm{CSR}=0.5)$; (d) collapsibility test $(\mathrm{CSR}=0.75)$.

mean stress and void ratio versus water content under different CSRs. It is clearly shown that the void ratio decreased with increases of the mean stress, and the compression curves under different CSRs all have better normality. When mean stress is low, the void ratio is almost constant, and when mean stress is high, the void ratio of the sample decreases with the water content increases during the GW test. The final stable void ratio of the $\mathrm{QW}$ and $\mathrm{GW}$ is close to the saturated 
structural soil under the same stress state, the void ratio of QW is slightly less than GW.

\subsection{Deviator strain}

Fig. 4 presents the evolutions of deviator strain against mean stress and deviator strain versus water content under different CSRs. It can be concluded that when the mean stress is low, deviator strain of sample is small, but with the mean stress increases, the deviator strain of the sample begins to increase. The deviator

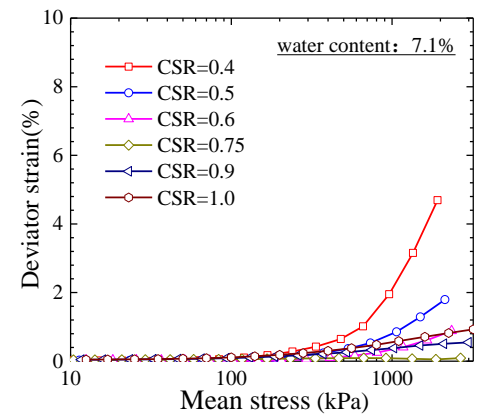

(a)

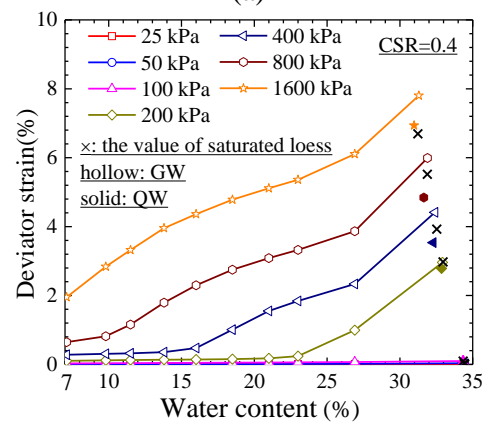

(b)

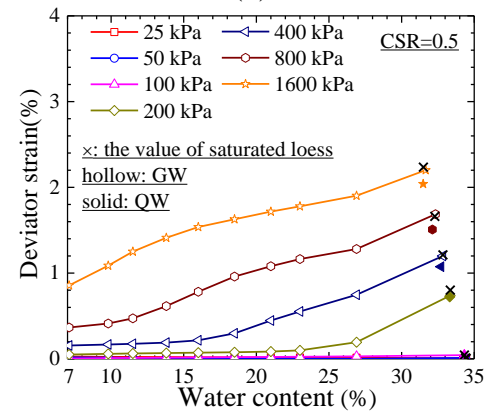

(c)

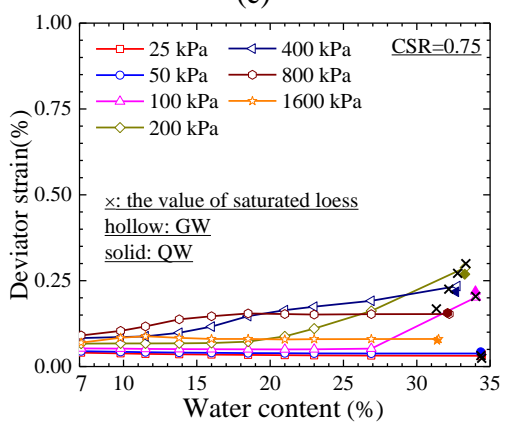

(d)

Fig. 4. Deviator strain evolutions of unsaturated structural loess under compression and collapsibility tests at different CSRs: (a) compression test; (b) collapsibility test $(\mathrm{CSR}=0.4)$; (c) collapsibility test $(\mathrm{CSR}=0.5)$; $(\mathrm{d})$ collapsibility test $(\mathrm{CSR}=0.75)$.

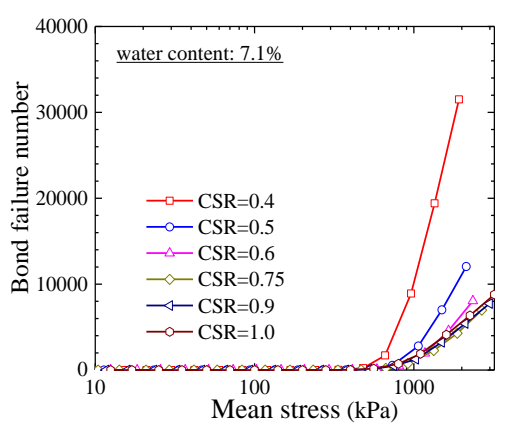

(a)

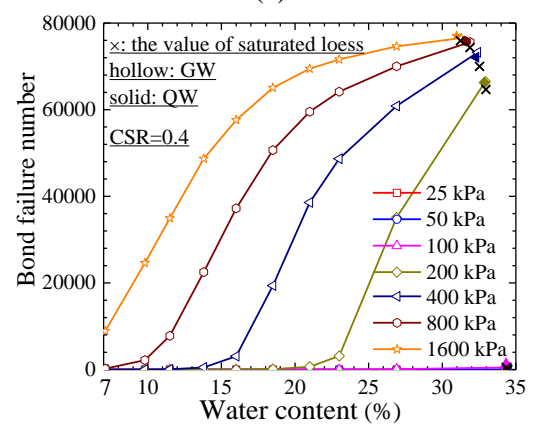

(b)

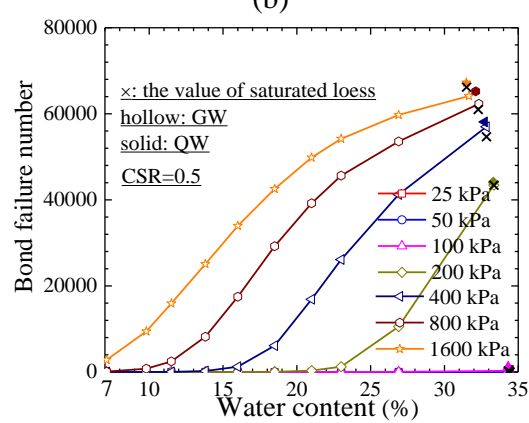

(c)

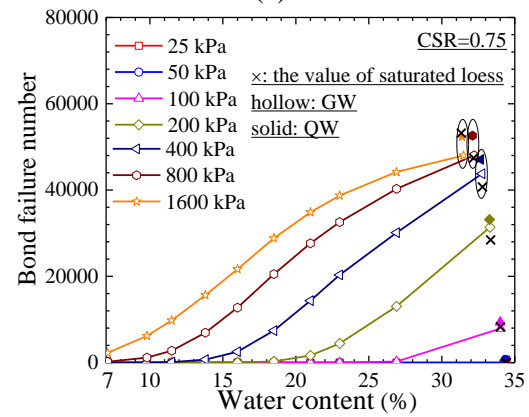

(d)

Fig. 5. Bond failure number evolutions of unsaturated structural loess under compression and collapsibility tests at different CSRs: (a) compression test; (b) collapsibility test (CSR=0.4); (c) collapsibility test $(\mathrm{CSR}=0.5)$; $(\mathrm{d})$ collapsibility test $(\mathrm{CSR}=0.75)$.

strain of the isotropic compression $(\mathrm{CSR}=1.0)$ is not 0 , but the deviator strain of the $\mathrm{CSR}=0.75$ is smaller than others CSR test results and nearly 0 , which was caused by the initial anisotropy of the sample. Because of the sample was preload, the vertical direction is stronger than the horizontal direction. So the vertical stress needs to be larger than the lateral stress for achieve the same displacement, and the simulation results show that the ratio of lateral stress to vertical stress is close to 
0.75 . When the stress ratio less than 0.75 , the deviator strain of the sample increases with the decreases of the stress ratio.

The stress and the stress ratio have a great influence on the deviator strain of unsaturated sample at collapsibility test. When the CSR is less than 0.75 , deviator strain and increment of the sample caused by wetting are small before the stress attains to threshold value. And when the CSR is larger than 0.75 or equals to 0.75 , the deviator strain of the sample under different stress are all small. The final stable deviator strain of QW and GW is close to the saturated structural loess under the same stress state, the deviator strain in the QW is slightly less than GW.

\subsection{Bond failure}

Fig. 5 presents the evolutions of bond failure number against mean stress and bond failure number versus water content under different CSRs. The bond begins to fail substantially until the mean stress reaches to threshold stress, and the threshold stress has well consistency with the yield stress on compression curve. In addition, when the stress ratio is less than or equals to 0.75 , the number of bond failure decreases with the increases of stress ratio. The increases of stress ratio results in decreases of bond failure number, but the compression curve almost unchanged. It indicates that in some specific cases, even if more bond no longer bears stress (bond failure), however, the stress can be bore by deformation between the particles. Therefore, in some cases, the difference of the amount of bond failure number do not necessarily causes significant difference in deformation.

At the process of $\mathrm{QW}$, the bond failure number undergoes growth process of slow, rapid and slow with the increases of water content. The final growth process slows when the number of bond failure attains to the total bond number. After the sample is stable, in both QW and GW, the bond failure number is close to the bond failure number of saturated structural loess under same stress state.

\section{CONCLUSIONS}

CSR compression and collapsibility tests were performed in this study to investigate unsaturated structural loess subjected to different water content. The evolutions of void ratio, deviator strain and bond failure number against vertical stress and water content were analyzed. The following conclusions can be made:

(1) The compression curve of the unsaturated structural loess under different stress ratios is almost coincident.

(2) Deviator strain and bond failure number are not sensitive to the water content at the low vertical stress.

\section{ACKNOWLEDGEMENTS}

This work was funded by China National Natural Science Foundation with Grant Nos. 51579178 and
51639008.

\section{REFERENCES}

1) Chen, Z.H., Fang, X.W., Zhu, Y.Q., et al. (2009): Research on mesostructures and their evolution laws of expansive soil and loess, Rock Soil Mechanics, 30(1), 1-11 (in Chinese).

2) Cundall, P.A., Strack, O.D.L. (1979): A discrete numerical model for granular assemblies, Geotechnique, 29(1),47-65.

3) Delage, P., Cui, Y.J., Antoine, P. (2005): Geotechnical problems related with loess deposits in Northern France//Proceedings of International Conference on Problematic Soils, Famagusta, 517-540.

4) Follmer, L.R.(1996): Loess studies in central United States: evolution of concepts, Engineering Geology, 45(1), 287-304.

5) Jefferson, I.F., Evstatiev, D., Karastanev, D., Mavlyanova, N.G., Smalley, I.J.(2003): Engineering geology of loess and loess-like deposits: a commentary on the Russian literature, Engineering Geology, 68(3), 333-351.

6) Jiang, M.J., Konrad, J.M., Leroueil, S. (2003): An efficient technique for generating homogeneous specimens for DEM studies, Computers and Geotechnics, 30(7): 579-597.

7) Jiang, M.J., Zhang, F.G., Hu, H.J., et al. (2014): Structural characterization of natural loess and remolded loess under triaxial tests, Engineering Geology, 181, 249-260.

8) Jiang, M.J., Zhang H.Z., Li T. (2019a): DEM analysis of isotropic compression tests on remolded and structured unsaturated loess, Chinese Journal of Geotechnical Engineering, 41(S2), 121-124.

9) Jiang, M.J., Sun, R.H., Li, T., et al. (2019b): A three-dimensional cementation contact model for unsaturated structural loess, Chinese Journal of Geotechnical Engineering, 41(S1), 213-216 (in Chinese).

10) Li, T., Jiang, M.J., Zhang, P. (2018): DEM analyses of oedometer and wetting tests on the unsaturated structured loess, Chinese Journal of Geotechnical Engineering, 40(S1), 39-44 (in Chinese).

11) Pu, Y.B., Chen, W.Y., Liao, Q.R. (2000): Research on CT structure changing for damping process of loess in Longdong, Chinese Journal of Geotechnical Engineering, 22(1): 52-57 (in Chinese).

12) Pye, K. (1995): The nature, origin and accumulation of loess, Quaternary Science Reviews, 14(7), 653-667.

13) Sun, P., Peng, J.B., Chen, L.W., et al. (2009): Weak tensile characteristics of loess in China - an important reason for ground fissures, Engineering Geology, 108(1), 153-159.

14) Xu, L., Dai, F.C., Tham, L.G., et al. (2011): Field testing of irrigation effects on the stability of a cliff edge in loess, North-west China, Engineering Geology, 120(1), 10-17. 